\title{
El pensamiento analógico en las filosofías analítica y pragmática
}

\author{
MAURICIO BEUCHOT \\ Instituto de Investigaciones Filológicas \\ Universidad Nacional Autónoma de México \\ hardie@servidor.unam.mx
}

\begin{abstract}
RESUMEN: En este artículo se intenta poner de relieve algunas relaciones entre la filosofía analítica y la filosofía pragmática o pragmatista. Una de ellas es el trabajo de algunos analíticos por reducir dicotomías (algo típicamente pragmatista), tales como analíticosintético (Quine) y hecho-valor (Putnam). Asimismo, se intenta hacer ver cómo en este afán de reducir dicotomías ha estado presente el concepto de analogía (iconicidad, en Peirce) y cómo puede seguir beneficiando a la discusión actual en la filosofía, destrabándola de varios puntos ciegos en que se encuentra; un ejemplo de ello, al que se aplica, es la polémica que se da, en la historiografía de la filosofía, entre los que Rorty llama los doxógrafos y los analíticos de argumentos.
\end{abstract}

PALABRAS CLAVE: analogía, filosofía analítica, filosofía pragmática, historia de la filosofía

En la filosofía analítica de última hora se ha notado un giro pragmatista, esto es, de estudio y recuperación de la filosofía de autores como Peirce, James y Dewey. ${ }^{1}$ Me parece que este giro pragmático de la analítica conlleva una búsqueda de reducir las tan extremas dicotomías que se han establecido hasta el momento (por ejemplo, entre teoría y praxis, entre analítico y sintético, entre hecho y valor, y creemos que también se puede aplicar, como veremos, para reducir la excesiva dicotomía que se ha marcado entre filósofos sistemáticos e historiadores de la filosofía).

En esta intencionalidad reductora de dicotomías que ha tenido el pragmatismo y que ahora adopta la filosofía analítica de corte pragmatista, se puede detectar un afán de mesura, de proporción, de integración. Y esto me ha hecho ver que este movimiento pragmático de la filosofía analítica permite la recuperación de pensamientos interesantes y fecundos dados en la historia de la filosofía. No se presenta como un progresismo o superacionismo historicista excesivo, en el que ya no hay que mirar lo anterior, porque ha sido superado y se encuentra muerto. De esta manera, me ha resultado interesante ensayar la recuperación de la idea de analogía para aplicarla, dentro de la filosofía analítica, a una pragmática analógica (igual

1 Cfr. J. Nubiola, La renovación pragmatista de la filosofía analítica, 2a. ed., Eunsa, Pamplona, 1996, pp. 26-27. 
que en la hermenéutica como hermenéutica analógica). Veamos algunos elementos que nos ayudarán a ahondar en esta intuición.

\section{CONFLUENCIA RECIENTE DE LA FILOSOFÍA ANALÍTICA Y LA FILOSOFÍA PRAGMATISTA O PRAGMÁTICA}

El mencionado giro pragmatista que se nota en la filosofía analítica significa varias cosas. ${ }^{2}$ Una de ellas es que se trata de recuperar la idea de Peirce de que la teoría se mide por su repercusión en la práctica: tiene que mostrarse en las ideas, los actos, las conductas y los hábitos que desata en el individuo. Otro elemento característico es la crítica que el propio Peirce hace del racionalismo extremo (como el de Descartes) y del empirismo extremo (como el de Hume y el de Comte). Aunque es atento a la ciencia, no es positivista, sino contrario a esa corriente. $\mathrm{Y}$ lo que me parece tal vez más interesante o importante es el intento de reducir las dicotomías, como la kantiana de fenómeno y noúmeno, la de teoría y praxis, la de hecho y valor, y la de analítico y sintético, según se ve en Dewey, Quine y Putnam; también una reducción precavida de la metafísica, para resaltar la semioticidad y la lingüisticidad del ser humano; una suavización de las exigencias epistemológicas de la verdad, como en James. Con todo, no parece auténtico, sino más bien espurio, el relativismo, contingentismo, particularismo y nominalismo de Rorty, en lo que ha sido llamado su "pragmatismo popular". A mi modo de ver, lleva a extremos exagerados e insostenibles los principios pragmáticos de James y Dewey. El pragmatismo original norteamericano tuvo como adalides a Peirce, James y Dewey.

Después, la filosofía pragmatista entroncó con la filosofía analítica, a través de seguidores de Peirce como Charles Morris, Clarence I. Lewis y Charles Hartshorne (aunque ninguno de los tres podría llamarse filósofo analítico, se acercaron mucho a ese ideal, y sirvieron de mediadores). ${ }^{3}$ También ayudaron a esto algunos autores críticos, como Sidney Hook, que

2 Cfr. J. Nubiola, "Neopositivismo y filosofía analítica: balance de un siglo", en Acta Philosophica (Roma), vol. 8, no. 2, 1999, pp. 216-218.

3 Morris fue discípulo de un connotado pragmatista, George H. Mead, pero entró en contacto con el positivismo lógico, lo cual se ve en su artículo "The Concept of Meaning in Pragmatism and Positivism" (Actes du Congrès International de Philosophie Scientifique, París, 1936), y trató de hacer puente entre ambas corrientes; además, participó con Carnap en la International Encyclopedia of Unified Science (1938). Lewis, que hizo contribuciones notables a la lógica, sobre todo en lógica modal, tiene dos artículos en una célebre antología de filosofía analítica compilada por Herbert Feigl y Wilfrid Sellars, intitulada Readings in Philosophical Analysis, Appleton-Century-Crofts, Nueva York, 1949. Los artículos son "Experience and Meaning" (pp. 128-145), "The Pragmatic Conception of the a Priori" (pp. 286-294) y "Some Logical Considerations Concerning the Mental" (pp. 385-392). Lewis fue coautor, con C.H. Langford, de una muy famosa Symbolic Logic (The Century, Nueva York, 1932). También 
fue en parte marxista y en parte un pragmatista poco ortodoxo, pero que estudió ciertos temas de filosofía analítica, como algunos relativos al lenguaje y a la ontología. ${ }^{4}$ Quizá también colaboraron otros situados a medio camino entre pragmática y analítica, como William K. Frankena (que dedicó parte de un libro sobre educación a estudiar a Dewey, a saber, Three Historical Philosophies of Education, ${ }^{5}$ donde aborda a Aristóteles, Kant y Dewey), ${ }^{6}$ Morton G. White (que tiene un artículo intitulado "The Analytic and the Synthetic: An Untenable Dualism"7 que aparece compilado en una importante antología de filosofía analítica), ${ }^{8}$ y Wilfrid Sellars, que puede ser considerado filósofo analítico, por lo menos positivista lógico. ${ }^{9}$ Pero hubo otros decididamente analíticos, que se han inspirado en el pragmatismo. Uno de ellos fue claramente Quine y, en alguna medida, su amigo Nelson Goodman. Otros posteriores han sido Hilary Putnam, Donald Davidson y Richard Rorty. Ya incluso a Davidson y a Rorty se los llama postanalíticos. Y este último, además, se autonombra neopragmatista.

Tal vez se podría hablar de Stanley Cavell y de otros como pragmatistas analíticos, pero son más lo primero que lo segundo. De lo que no cabe duda es que Quine y Putnam pertenecen a esa corriente analítica que entronca con el pragmatismo. Esto se ve sobre todo en su discusión de las dicotomías demasiado extremas y simplistas. En el caso de Quine, la dicotomía entre analítico y sintético; en el caso de Putnam, la dicotomía entre hecho y valor. Quine muestra la influencia de Peirce, del cual reseñó, en 1933, para

aparece en esa antología de filosofía analítica alguien muy vinculado con el pragmatismo, a saber, C.L. Stevenson, con el artículo "The Nature of Ethical Disagreement" (pp. 587-593).

${ }^{4}$ Por ejemplo, The Quest for Being, St. Martin's Press, Nueva York, 1961. Cfr. C. West, The American Evasion of Philosophy. A Genealogy of Pragmatism, The University of Wisconsin Press, Madison, 1989, pp. 114-124. De la relación crítica de Hook con el pragmatismo da testimonio, entre otros, su libro John Dewey: An Intelectual Portrait, John Day, Nueva York, 1939.

5 Scott, Foresman and Co., Glenville, Il., 1965.

${ }^{6}$ Cfr. W.K. Frankena, Tres filosofías de la educación en la historia. Aristóteles, Kant, Dewey, Unión Tipográfica Editorial Hispano-Americana, México, 1968, pp. 242-336.

7 En el volumen colectivo John Dewey: Philosopher of Science and Freedom, The Dial Press, Nueva York, 1950.

8 La antología es la de L. Linsky (comp.), Semantics and the Philosophy of Language, University of Illinois Press, Urbana/Chicago/Londres, 1952, pp. 272-286.

9 Wilfrid Sellars, autor, por ejemplo, de Lenguaje, percepción y realidad (Tecnos, Madrid, 1968), se ocupa de estos temas típicamente pragmatistas y analíticos aludidos en el título de su libro. Viene del pragmatismo (con el cual estuvo relacionado su padre Roy Wood Sellars), y es considerado por Hilary Putnam como el positivista lógico americano más típico; lo pone como ejemplo del "realismo metafísico" del positivismo lógico que siempre desea combatir. También los positivistas lógicos volvieron su vista al pragmatismo, aunque un poco después. En este sentido, es algo muy curioso darse cuenta de que el filósofo neopositivista inglés Alfred J. Ayer escribió un libro sobre pragmatismo norteamericano, a saber, The Origins of Pragmatism (Macmillan, Londres, 1968), acerca de Peirce y James. 
el vol. 19 de la revista Isis, el segundo tomo de los Collected Papers, editado por Charles Hartshorne y Paul Weiss en 1932; precisamente el tomo de las cosas de lógica. Puede decirse que buena parte de la lógica de Quine proviene de Peirce, sin que se haga mención explícita. ${ }^{10} \mathrm{Y}$ probablemente su adhesión al conductismo tan fuerte no sólo provenga de su amistad con B.F. Skinner, sino también de la reconstrucción conductista que Morris hace de la semiótica de Peirce. Putnam se inspira en Peirce, al que toma muy en cuenta en sus trabajos, ${ }^{11}$ y del que retoma el ideal lógico y de salvaguardar el realismo a pesar de atender al trascendentalismo kantiano. Igualmente se inspira mucho en James, a quien sigue en la reducción de la dicotomía entre teoría y praxis, y en Dewey, del que adopta la reducción de la dicotomía entre hecho y valor, al igual que la integración de la axiología como explicación de las mismas opciones filosóficas; toma asimismo de él el ideal de la renovación de la filosofía, precisamente para aplicar métodos muy competentes a problemas muy humanos.

A mí me simpatiza sobre todo esta corriente de analíticos y pragmatistas que se inspiran en Peirce. (De hecho yo trato de retomar muchas ideas suyas.) En cuanto a James, me produce reservas su idea de la verdad, tan abierta. No me disgusta la influencia de Dewey y lo que de él se puede recuperar en cuanto a la democracia. Tal vez no comparto tanto lo que dice de la educación. Me parece muy discutible la posición de Rorty, que rechaza in toto a Peirce, y se refugia en James; dice acudir a Dewey, pero lo hace en menor medida. Con James hay el peligro de que oscila entre el relativismo y el subjetivismo. Eso me resulta inaceptable; por ello guardo mis reservas con respecto al neopragmatismo de Rorty, que sigue mucho a James. En cambio, Peirce siempre trata de salvaguardar la objetividad, con su teoría de los universales y las leyes científicas, e incluso con su teoría de la verdad como el acuerdo tendencial de la comunidad ideal de investigación y comunicación. Recuérdese que Quine rechaza la verdad tomada como pura convención. ${ }^{12} \mathrm{Y}$ el holismo de la verdad, que toma de Pierre Duhem,

10 Por ejemplo, su solución a la paradoja de la implicación material; véanse las reseñas de Quine en Isis, vol. XIX, 1933, pp. 220-229; vol. XXII, 1936, pp. 285-297 y 551-553. Esto es lo que trato de demostrar en mi libro Implicación, falacia y argumento, Universidad de Guadalajara, Guadalajara (México), 1997.

11 Cfr. H. Putnam, El pragmatismo. Un debate abierto, Gedisa, Barcelona, 1999 (1a. ed. en inglés, 1992). Allí se opone al relativismo "neopragmático" de Rorty (pp. 106-108).

12 Cfr. W.V.O. Quine, "Truth by Convention”, en H. Feigl y W. Sellars (comps.), op. cit., pp. 250-273, donde cuestiona el significado de la verdad por convención. Dice que si las matemáticas son verdaderas por convención, también sus principios deben serlo, y entonces lo analítico sería verdadero por convención; pero, como él pone en duda la diferencia demasiado tajante entre lo analítico y lo sintético, también cuestiona el que las matemáticas y la lógica sean analíticas, ya que las definiciones analíticas sirven para transformar verdades, no para 
tiene cierta coincidencia con esa idea de la verdad global y tendencial, como ideal regulativo, de Peirce.

Hay dos cosas en esta recepción del pragmatismo por parte de la filosofía analítica que me parece que vale la pena resaltar: una es la reducción de la dicotomía entre hecho y valor, que tanto separaba Hume con su idea de que el paso del primero al segundo era una falacia naturalista; idea repetida en cierto modo por Kant y, ya con ese nombre de falacia naturalista, por G.E. Moore.

La otra es la reducción de la dicotomía entre fenómeno y noúmeno, de Kant, ya que Peirce dice explícitamente que no cree en esa separación ni en esas dualidades que tienen una parte que resulta incognoscible. Pero creo que también el pragmatismo nos puede servir para reducir otra dicotomía importante en la filosofía reciente, y que con su desmedida distensión ha hecho mucho daño, ha causado mucha discusión y, por lo mismo, muchas disputas estériles. Se trata de la dicotomía entre hecho e interpretación, que popularizó Nietzsche. En efecto, cuando él asevera que ya no hay hechos, sino sólo interpretaciones, está aludiendo a la dicotomía kantiana entre fenómeno y noúmeno — que Schopenhauer quiso superar con su idea de que el noúmeno se puede aprehender, pero no por el intelecto, sino por la voluntad de representación-y que Nietzsche quiere superar con la voluntad de poder, la cual nos haría ver el noúmeno detrás de los fenómenos, o el sujeto detrás de la máscara. Y como esta última dicotomía implica la nihilista anulación del noúmeno a favor del fenómeno, y éste es el lado subjetivista del conocer, queda sólo la interpretación subjetiva, que se instala en el fenómeno, y desaparece el noúmeno, que es lo que podría guardar la objetividad del hecho. En realidad se supone la dicotomía, y así se sacrifica una de sus partes. Siempre se sacrifica una de ellas, precisamente la más débil; esto es, la menos susceptible de conocimiento (por considerarla envuelta en las brumas metafísicas, como sucede con el noúmeno). En cambio, creo que se deben salvaguardar los dos lados, en la proporción justa. Yo aceptaría el dictum de Nietzsche pero con cierta interpretación; es decir, en el sentido de que no hay hechos puros, aislados de toda interpretación, sino siempre hechos interpretados, o mediados por nuestra interpretación. Con todo, eso no implica que no haya hechos, pues se nos dan en la interpretación, así como los noúmenos se nos dan envueltos en los fenómenos, y tenemos que destilarlos mediante la acción purificadora de nuestra abstracción cognoscitiva. Está bien, no hay hechos puros, sino sólo interpretados; los hechos puros no me interesan, ya sé que sólo accedemos a ellos mediando la in-

fundarlas (cfr. p. 258). El artículo apareció por primera vez en un homenaje a Whitehead, en O.H. Lee (comp.), Philosophical Essays for A.N. Whitehead, Longmans, Green and Co., Nueva York, 1936. 
tepretación; pero con eso me basta. Hay hechos: se nos dan envueltos en nuestras interpretaciones, y tenemos que saber destilarlos, para aprender de ellos las leyes universales que debemos abstraer con nuestro intelecto. Hay hechos, y se nos dan en las interpretaciones. Es un realismo interpretativo, contextual, que es un realismo analógico; una hermenéutica que no destruye a la ontología o metafísica, sino que la asume, se asumen las dos, y no para irse destruyendo nihilistamente, como quiere Vattimo, sino de manera que se influyan mutuamente, que se purifiquen, que se pongan en su sitio, que se den su exacta proporción, que coloquen al otro dentro de sus justos límites proporcionales.

\section{EL PRAGMATISMO EN LA CUESTIÓN DE LA FILOSOFÍA Y SU HISTORIA}

La pragmática contemporánea nos muestra que el acudir a la historia de la filosofía tiene un interés dialogal o dialógico como el que tiene la discusión con nuestros contemporáneos; esto es, nos muestra que es imprescindible. En efecto, ella misma nos enseña que no existe una historia sin reconstrucción interpretativa, pero tampoco historia que sea pura reconstrucción; se produce un tira y afloja entre la historiografía objetivista y la interpretación en la que introducimos nuestra individualidad cultural. Los textos filosóficos ya no tienen los mismos destinatarios; tienen otros: los lectores modernos, que les hacen perder su autonomía original. Si no se hace una interpretación, no hay contacto con esos lectores nuevos. Por otra parte, tampoco podemos hacer historia cambiando lo que quiso decir el autor. Por lo tanto, nos queda la abrumadora responsabilidad de no traicionar al autor y, además, de decir lo que quiso decir de modo que lo entiendan nuestros coetáneos. Esto es, nuestra pragmática consiste en recuperar la intencionalidad del autor y comunicarla al lector contemporáneo. Difícil equilibrio: pragmatizar es contextualizar en la época pasada y conectar con el presente; y por lo general incurrimos en algún extremo. O somos más historiógrafos o somos más analíticos de argumentos. Incluso me atrevería a decir que, dadas las corrientes de nuestra época, estamos más inclinados a ser menos historiógrafos, sobre todo por la distancia cultural. Y también me parece que si ese riesgo es ineludible, lo mejor es sacar el mayor provecho del énfasis puesto en la historia de la filosofía como una especie de diálogo con los filósofos anteriores como si fueran recientes. ${ }^{13}$

13 Cfr. R. Rorty, "The Historiography of Philosophy: Four Genres", en id. (comp.), Philosophy and its History, Cambridge University Press, Cambridge, 1987, pp. 49-75. Aquí habla de cuatro géneros historiográficos de la filosofía: la reconstrucción racional, que trata de ver las razones o argumentos de los filósofos; la reconstrucción histórica, que trata de contextuar a los filósofos en sus épocas, y nos dice que tuvieron grandes ideas pero que no las pudieron llevar a cabo por la limitación de sus tiempos; la Geistesgeschichte, que pone de relieve los 
En este sentido, y gracias a la pragmática, me siento como en un diálogo actual dentro de un debate contemporáneo cuando comparo tesis y argumentos de Duns Escoto y Suárez con tesis y argumentos de David Wiggins y Michael Slote en cuanto a la teoría de la sustancia. Hay una continuidad, una especie de progreso que se da reelaborando argumentos de los filósofos. Aunque las tesis son análogas, no son las mismas. Por ejemplo, la teoría de los nombres propios de Ockham se parece mucho a la de Russell, mientras que la de G. de Sherwood se acerca a la de Frege y algo a la de Strawson; San Vicente Ferrer se pelea con todos ellos e introduce tesis tipo Quine. ${ }^{14}$ Pero no son lo mismo, y en ese no ser lo mismo nos enriquecen con otros caminos y argumentos. Un discípulo de Jaakko Hintikka, a saber, Simo Knuutila, dice que Santo Tomás es el Kripke de la Edad Media, mientras que Duns Escoto es el David Lewis de la misma, por la semejanza de posturas. Pero lo que importa son los debates con aquellos filósofos con los que podemos lograr alguna conmensuración.

Dos preguntas rigen el trabajo aquí: ¿cuál es la importancia de la historia de la filosofía para hacer filosofía? y ¿cuál es un buen método para hacer historia de la filosofía? Frente a las polémicas acerca de si tenemos que acercarnos más a la recuperación del pasado o inclinarnos más a la comunicación del pasado relevante para los lectores del presente, me parece que un buen aporte metodológico nos lo brinda la conjunción de la pragmática y la teoría de la argumentación, tal como lo hace Hintikka en uno de sus ensayos. ${ }^{15}$ Es decir, la pragmática nos enseña que, a pesar de que siempre se introduce nuestra subjetividad cultural en la historia que hacemos, algo podemos captar de lo que quiso decir el autor. Con todo, por ello mismo nuestra actitud historiográfica tiene limitaciones, y hay que poner un mayor énfasis en el diálogo argumentativo con los filósofos que aparecen en esa historia. Además, veo que en el diálogo con los autores del pasado se percibe lo mismo que ocurre en el diálogo con los actuales: hay condiciones para que el diálogo sea fructífero, y por eso me parece que al filósofo lo ayuda, sobre todo, atender a aquellos autores y corrientes que comparten en mayor medida sus principios y/o reglas (pues el diálogo puede llegar a hacerse imposible), y que más se acercan a sus intereses, te-

problemas, y trata de explicar por qué fueron planteados; y la doxografía, que nos expone lo que los tradicionalmente llamados "filósofos" han dicho sobre los tradicionalmente llamados "problemas filosóficos". Rorty desprestigia la doxografía, y dice que los tres restantes son indispensables; pero también llama la atención hacia lo que denomina la "historia intelectual" de una época, más vasta que la historia filosófica, dentro de su idea de qué es lo que puede ayudar a mantener la conversación filosófico-cultural viva y fecunda.

14 Cfr. M. Beuchot, "La semántica de los nombres propios en la filosofía medieval", en Análisis Filosófico, vol. X, 1990, pp. 69-88.

15 Cfr. Hintikka, "The Role of Logic in Argumentation", The Monist, vol. 72, 1989, pp. 2 y ss. 
mas y métodos. Será siguiendo esa línea como obtendrá el mayor provecho de su diálogo con filósofos anteriores, al analizar sus planteamientos, sus respuestas y sus argumentos.

Como se ve, entiendo la metodología de la historia de la filosofía más como un diálogo argumentativo con los filósofos anteriores que como una historiografía inacabable por los detalles que busca para una pretendida comprensión casi absoluta. Claro que exijo lo más que se pueda de contexto histórico y filológico, pues de otra manera no se pueden entender ciertos problemas y las respuestas que daban los autores; pero tiendo a ver la historia de la filosofía preponderantemente como un diálogo con las tesis y argumentos de los filósofos anteriores muy parecido al diálogo que mantenemos con los filósofos actuales. Además, creo que eso es lo que en la práctica hizo ese gran historiador de la filosofía medieval que fue Étienne Gilson, quien, por lo demás, estuvo en contacto con el pragmatismo, y en cierta medida escribió como interlocutor de James, tal como se ve en su libro The Unity of Philosophical Experience, que es resultado de unas conferencias dictadas en la William James Society. ${ }^{16}$

\section{ANALÍTICA, PRAGMATISMO Y ANALOGÍA}

Dado lo anterior, la analítica pragmática me permite mirar hacia pensamientos lejanos en la historia y que, sin embargo, pueden ser buena fuente de inspiración para nuestro trabajo filosófico de hoy en día. Un caso es la recuperación que he intentado, para la filosofía analítica pragmática (lo mismo que para la hermenéutica), de la idea de analogía, que viene de los pitagóricos, pasa por Platón y Aristóteles, atraviesa toda la Edad Media, decae y casi se pierde en la modernidad, pero es rescatada en el Barroco y en el Romanticismo, y vuelve a perderse en la época contemporánea, hasta que ahora retorna por sus fueros. Y no soy un caso aislado de esta recuperación. Se encuentra algo semejante en James F. Ross y en Alejandro Llano, ambos pertenecientes, cada uno a su modo, a la vertiente analítica de la filosofía, y ambos, también a su manera, tocados por el giro pragmático o pragmatista de este género de filosofía. En efecto, a diferencia de otros filósofos analíticos, más "sintacticistas" o semánticos, tales como I.M. Bochenski y S. Breton, ${ }^{17}$ que han querido formalizar el discurso analógico y obtener una lógica de la analogía con los recursos de la lógica matemática, y que han llegado a resultados bastante pobres por acabar en cálculos tan pesados

16 Cfr. É. Gilson, La unidad de la experiencia filosófica, Rialp, Madrid, 1960.

17 I.M. Bochenski, "On Analogy", en A. Menne (comp.), Logico-Philosophical Studies, Reidel, Dordrecht, 1962, pp. 97-117; id., La lógica de la religión, Paidós, Buenos Aires, 1967, pp. 158 y ss.; S. Breton, Foi et raison logique, Eds. du Seuil, París, 1971, pp. 120 y ss. 
que son casi inutilizables, Ross y Llano, más pragmáticos, han optado por reconstrucciones no formales de la analogía, sino de lenguaje ordinario, en el sentido de Wittgenstein y Austin, y creo que han logrado un mayor esclarecimiento. De esta manera, uno de ellos (Ross) nos ha entregado una elucidación filosófico-lingüística pragmática de la analogía que la hace apta o nos la da dispuesta para ser utilizada en la actualidad sin que suene a antigualla; ${ }^{18}$ y el otro (Llano) la aplica a problemas acuciantes de nuestro tiempo más reciente, llamado de tardomodernidad o posmodernidad.

Veamos como ejemplo de esto a Alejandro Llano, profesor de la Universidad de Navarra, en Pamplona. Formado en el tomismo, estudió después el kantismo y la fenomenología, pero pasó a estudiar la filosofía analítica, en la que descolló mucho (como muestra está su libro Metafísica y lenguaje, Eunsa, Pamplona, 1984), y, por sus estudios sobre pragmatismo y posmodernidad, se dedicó a estudiar ese fenómeno de lo tardomoderno o posmoderno, en su libro La nueva sensibilidad. ${ }^{19}$

Haciéndose eco del propio título del libro, Llano plantea una nueva sensibilidad que ha de surgir en estos tiempos de posmodernidad, so peligro de que se acabe toda cultura. Pues bien, esa nueva sensibilidad es analógica. Va contra el univocismo de los positivismos y cientificismos, pero sin caer en el extremo de la ambigüedad caótica. Frente a Foucault, quien dice que la analogía ya no es posible, porque las cosas han perdido su relación de semejanza con las palabras, Llano plantea que precisamente en esa tierra media en la que transitan de unas a otras se encuentra la posibilidad de volver a ajustarlas, y eso es el terreno analógico.

Para discurrir por esta tierra media - dice- $[\ldots]$ es preciso echar mano de una lógica que se inserta entre la fría lógica de la homogeneidad moderna y la 'lógica' posmodernista de lo irremediablemente heteróclito. Entre la maciza univocidad y la variabilidad dispersa, se mueve [...] el discurso analógico. ${ }^{20}$

Es otro modo de pensar, que respeta las variaciones de lo real, lo diferente, un tanto como la dialéctica, pero sin caer en sus excesos de diferencia. Reduce las contraposiciones, y hasta las rompe, mas sin derivar a lo caótico; busca la conciliación, la gradualidad y lo complementario. Esto es muy importante.

18 James F. Ross, eminente filósofo de orientación analítica, que ha estudiado mucho la analogía desde la semántica y la pragmática (Portraying Analogy, Cambridge University Press, Cambridge, 1981), y ha señalado que el lenguaje analógico predomina sobre el unívoco en nuestra habla cotidiana.

19 A. Llano, La nueva sensibilidad, Espasa Universidad, Madrid, 1988.

${ }^{20}$ Ibid., p. 215. 
El discurso analógico ve al hombre con una naturaleza histórica. Por eso acude a la poética como sabiduría, que puede hacer relatos y encontrar los fundamentos de los relatos sin acudir a extraños metarrelatos. Es una poética de la analogía, para este pensar analógico de la nueva sensibilidad. Llano acude a la clarividente exposición que de la analogía hace Octavio Paz. ${ }^{21}$ Trata de fusionar la estética de la ironía y la estética de la analogía, para salvaguardar lo individual sin perder lo universal. Así, se nos llama la atención acerca de que la realidad es una realidad matizada, por lo cual el

esencialismo debe ser matizado (no abandonado). El esencialismo que hoy empieza a mantenerse de nuevo - especialmente en la filosofía analítica del lenguaje - tiene una índole realista. Lo cual equivale a decir, por una parte, que sostiene la realidad de las esencias o modos fundamentales de ser. Mas, por otra, tal realismo también implica que esas esencias reales no son esencias puras: no son ideas trasladadas intactas a la realidad desde algún mundo platónico o algún "tercer mundo" fregeano, hartmanniano o popperiano. Esas maneras fundamentales de ser existen como estructuras ontológicas de individuos variados y variables. ${ }^{22}$

Es decir, el universal no se da aislado, se da en los individuos. Allí tenemos que reconocerlo.

Eso hace que la realidad, que es variable y no unívoca, sea contextual. Este devenir y esta polisemia sólo puede ser salvaguardada por la analogía. La primacía de las oraciones sobre las palabras hace que la analogía tenga primacía semántica sobre la univocidad. (Yo añadiría que tiene igualmente una primacía pragmática.) Por ello también el lenguaje es contextual, pero sin caer en un holismo hermenéutico donde todo tiene que ver con todo y no hay límites para la relación, límites que dan significado y evitan el relativismo. Las palabras aportan la fijeza, pero en la oración adquieren variabilidad, sufren variación; por ello la analogía es lo que las sujeta sin que pierdan su carácter de variables.

La analogía lingüística permite salvar los fenómenos: no sacrificar la unitaria diversidad de lo real a nuestras exigencias significativas. El lenguaje analógico es, al tiempo, extensional e intensional. Lo cualitativo de la realidad queda guardado en la dimensión intensional del lenguaje. Y como [...] el mantenimiento de lo cualitativo es la salvaguarda del realismo, resulta que el carácter intensional del lenguaje salva su naturaleza intencional, es decir, su constitutiva referencia a la realidad. A través de las palabras —y más allá de ellas-,

21 Esto se aprecia sobre todo en el libro de O. Paz, Los hijos del limo. Del romanticismo a la vanguardia, 2a. ed., Seix Barral, Barcelona, 1974.

22 A. Llano, op. cit., p. 221. 
miramos al mundo, moviéndonos en un ámbito intermedio entre el sujeto y la realidad. ${ }^{23}$

Llano cita a J.F. Ross, de quien hemos hablado, y que reivindica el predominio de la analogicidad sobre la univocidad en el lenguaje. Además, se apunta a la actualidad de la retórica, al igual que de la poética, como techne del lenguaje en contexto. Pero con la atención en el contexto particular, desde la luz de lo universal, se evita el relativismo sofístico. "La nueva sensibilidad es un realismo: un pensar meditativo que se abre agradecidamente a lo real. La racionalista y unidimensional actitud de dominio ha de ser sustituida por esa originaria unidad de consideración y de acción que es la epimeleia, el cuidado." ${ }^{24}$ En ese cuidado de sí, de los demás y de las cosas consiste la cultura; ella implica una mímesis que no es copia, sino reproducción analógica. La epimeleia es analógica unidad de lo diferente. Incluso puede decirse que tiene un aspecto femenino ascendente frente a la masculinidad imperante, que no es debilitamiento, sino hondura, no es negación, sino abnegación. Es un amor de benevolencia profunda.

Eso nos conecta con la empatía, que es la que realiza ese amor. Y Llano la encuentra en la Einfühlung, cuyo estudio lleva a cabo Edith Stein. Es más que la simpatía, es lo que entabla la intersubjetividad. Es incluso anterior al lenguaje, y sólo un lenguaje analógico puede expresarla:

Sin que medie palabra, yo puedo hacerme cargo de la conducta ajena y pensar: en su lugar, yo lo habría hecho también así. Sólo el lenguaje analógico logra moverse en ese ámbito del en y del entre. Encuentra unidad - 'Ein-fühlung' - en la alteridad. Reconoce la variedad y variación de los focos, ángulos y perspectivas presentes en la experiencia común. Y supera tal diversidad — sin eliminarlacon una naturalidad que es connaturalidad. ${ }^{25}$

En efecto, otro nombre de la empatía es la connaturalidad, el conocimiento por connaturalidad, en el cual, más allá de lo puramente ideativo, interviene también lo afectivo. Y es donde la analogía (el conocimiento analógico) se pone eminentemente en práctica. Tal conocimiento no puede sino llevar a una praxis de amistad.

\section{CONCLUSIÓN}

William James decía que el pragmatismo era poner nombres nuevos a ideas viejas; y algo tenía de razón en ello. La vertiente pragmática o pragmatista

$\begin{array}{ll}23 & \text { Ibid., p. } 223 . \\ 24 & \text { Ibid., p. } 225 . \\ 25 & \text { Ibid., p. } 230 .\end{array}$ 
de la filosofía analítica (al acudir a Peirce, a James y a Dewey en un tiempo en que sólo se atendía al último artículo del analítico en boga) ha tomado conciencia de que pensadores anteriores tienen mucho que decirnos sobre nuestros problemas actuales. De esta manera reduce la dicotomía que se había querido trazar entre filósofos sistemáticos e historiadores de la filosofía, y hace que los primeros salgan de su presuntuoso desconocimiento de la historia de la filosofía, y los segundos salgan de su montón de detalles y se animen a sacar tesis y argumentos que puedan ser propuestos con provecho para nuestra filosofía de hoy.

Apoyado en ello me atreví a ensayar y desarrollar la intuición de que hacía falta un planteamiento analógico que mediara en la lucha entre el univocismo y el equivocismo que parece ser nuestra filosofía reciente, ya demasiado enredada y bloqueada por eso mismo. Con ello me persuadí de que una filosofía analítica pragmática que recupere la idea de la analogía, en la historia, nos llevaría a una pragmática analógica que superara el impasse en el que se muestra entrampada nuestra actual discusión filosófica.

Recibido el 26 de septiembre de 2001; revisado el 21 de enero de 2002; aceptado el 19 de marzo de 2002 